\section{Discussion}

Hemangioendothelioma is a rare cardiac tumor, and just a few cases treated with surgical intervention are reported in the English literature. ${ }^{1-3}$ The tumor in the case we report here was huge and clearly encapsulated by calcification and fibrous connective tissue, which is why we could enucleate the tumor without difficulty.

Hemangioendothelioma is classified as an intermediate malignancy that sometimes metastasizes and recurs. ${ }^{4,5}$ This might indicate that we should have undertaken additional therapy, but Allaire and colleagues ${ }^{4}$ have reported that irradiation therapy or chemotherapy resulted in only palliation, whereas Hongquan and associates $^{1}$ revealed the prognosis of the hemangioendothelioma was relatively good once it was completely resected. In the present case, the tumor was successfully enucleated, and therefore we decided not to undertake additional therapy. The patient was then followed for about 3 years, with no sign of recurrence or metastasis.
Although it appears to have been clinically benign, this is an unprecedented giant tumor that showed an unusually proliferative pattern, and therefore further close follow-up is inevitable.

\section{References}

1. Hongquan Y, Hua R, Quancai C, Qi M, Xiaocheng L, Letian X. Cardiac hemangioendothelioma. J Cardiovasc Surg. 1998;39:655-8.

2. Gasparovic H, Anic D, Saric D, Gasparovic V, Djuric Z, Jelic I. Surgical excision of a hemangioendothelioma of the left ventricle. Ann Thorac Surg. 2002;74:914-6.

3. Ichikawa H, Kaneko T, Obayashi T, et al. Surgical treatment of malignant hemangioendothelioma originated from the right atrium. Kyobu Geka. 1997;50:67-70.

4. Allaire FJ, Grimm CA, Taylor LM, et al. Primary Hemangioendothelioma of the heart. Report of a case treated with irradiation and cyclophosphamide. Rocky Mt Med J. 1964;61:34-7.

5. Marchiano D, Fisher F, Hofstetter S. Epithelioid hemangioendothelioma of the heart with distant metastases. J Cardiovasc Surg. 1993;34:529-33.

\title{
Lymphangiomatous hamartoma: Cause or bystander of the isolated chylopericardium?
}

\author{
Charalambos Zisis, MD, $\mathrm{PhD},{ }^{a}$ Dimitra Rontogianni, $\mathrm{MD}, \mathrm{PhD},{ }^{\mathrm{b}}$ Eliana Charalambous, $\mathrm{MD}^{\mathrm{c}}$ and \\ Ion Bellenis, $\mathrm{MD}, \mathrm{PhD}^{\text {a }}$ Athens and Crete, Greece
}

$\mathrm{I}$ solated chylopericardium is an extremely rare pathologic entity, and about its cause there is a series of reasons sporadically reported in the literature. Lymphangiomatous hamartoma, a benign tumor of lymphangiomatous origin sparsely located exclusively to the mediastinum, has been considered one of the causes of the chylopericardium.

\section{Clinical Summary}

A 25-year-old male smoker of 7 pack-years was referred to our department from a district hospital for rapidly recurrent pericardial effusion (Figure 1) diagnosed 15 days before and showing no response to medication. During the 2 previous days, this progressively increasing effusion had caused clinical and echocardiographic features of pericardial tamponade and had been submitted twice to pericardiocentesis, with removal of $2.5 \mathrm{~L}$ and $800 \mathrm{~mL}$ of milky fluid, respectively. The laboratory results

\footnotetext{
From the Departments of Thoracic Surgery ${ }^{\mathrm{a}}$ and Pathology, ${ }^{\mathrm{b}}$ Evangelismos General Hospital, Athens, Greece, and the Intensive Care and Coronary Care Unit, "Venizelio" Hospital, Iraklion, Crete, Greece.

Received for publication April 29, 2005; accepted for publication May 20, 2005 .

Address for reprints: Charalambos Zisis, MD, PhD, 17A, Patriarchou Grigoriou str, 16674 Glyfada, Greece (E-mail: chzisis@otenet.gr).

J Thorac Cardiovasc Surg 2005;130:1201-2

$0022-5223 / \$ 30.00$

Copyright (C) 2005 by The American Association for Thoracic Surgery doi:10.1016/j.jtcvs.2005.05.025
}

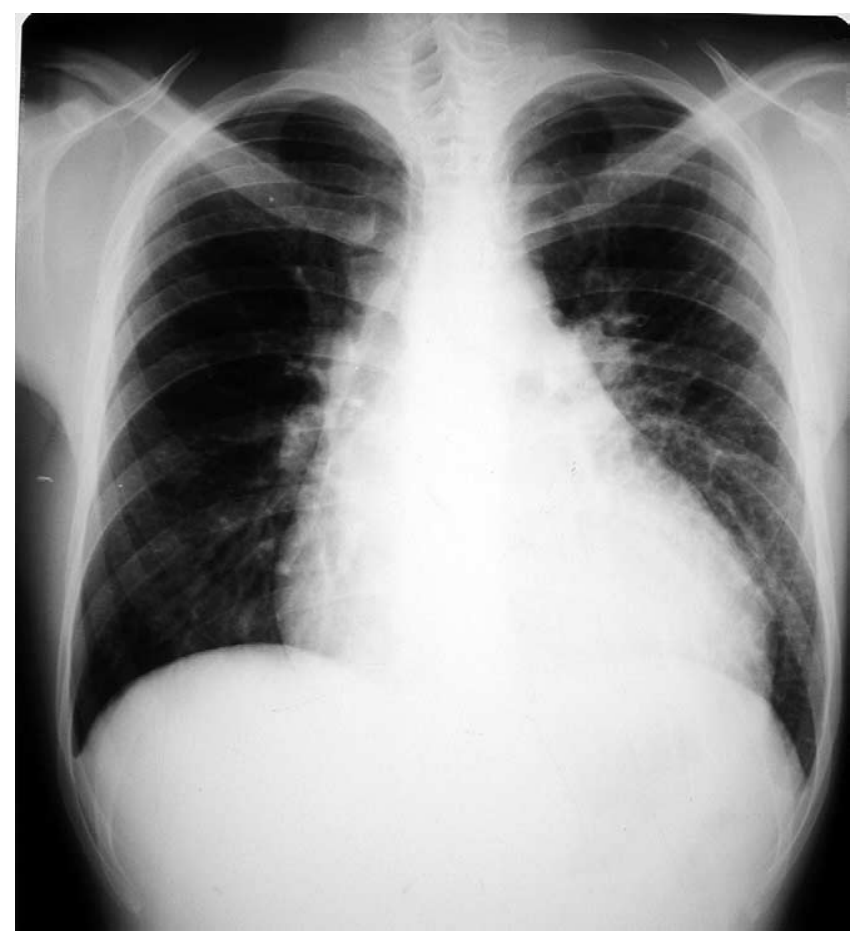

Figure 1. Preoperative chest $x$-ray film demonstrating enlargement of the cardiac silhouette contour caused by tamponade. 
of the fluid revealed the following: triglycerides, $944 \mathrm{mg} / \mathrm{dL}$; cholesterol, $76 \mathrm{mg} / \mathrm{dL}$; glucose, $116 \mathrm{mg} / \mathrm{dL}$; total proteins, 3.7 $\mathrm{g} / \mathrm{dL}$; and lactic dehydrogenase, $707 \mathrm{U} / \mathrm{L}$. Computed tomography of the chest confirmed the pericardial effusion, and the patient underwent a left anterior thoracotomy for pericardial window, when loose and flabby tissue anterior to the pericardium was discovered unexpectedly. After a second diagnostic investigation (Figure 2), access through a median sternotomy was chosen, and all tissue located at the anterior mediastinum, which developed diffusely as myxomatoid and adipose tissue without concrete macroscopic contour, was totally resected with the adjacent pericardium. The patient continued to receive total parenteral nutrition for the whole postoperative period after the first and second operations until drainage entirely stopped, and the tubes were removed on the 10th postoperative day. The patient is doing well 1 year after, without any sign of recurrence, and a small amount of fluid is checked echocardiographically. The pathologic examination of the specimen showed hyperplastic lymphangiomatous spaces partially with muscular wall and some others with thin wall developing into the pericardium and the adjacent fibrous and fatty tissues of the anterior mediastinum. These histopathologic findings had the character of lymphangiomatous hamartoma and were accompanied by chronic pericarditis and reactive lymphadenitis in a total of 16 lymph nodes.

\section{Discussion}

Isolated chylopericardium has been reported in a series of pathologic conditions, such as in chest trauma, in thrombosis or catheterization of the subclavian vein, after cardiac and thoracic surgery procedures, and in rare tumors, such as lymphatic hamartomas or lymphangiomas. ${ }^{1}$ However, the entity of isolated primary idiopathic chylopericardium, sporadically reported in the literature if no obvious cause can be established, remains obscure. ${ }^{2}$

Diagnosis is usually made by means of the pericardiocentesis in patients with pericardial effusion, which is demonstrated to be chylopericardium. Whether it is a primary or secondary chylopericardium remains to be investigated with the remaining diagnostic work-up, including computed tomographic scanning and sometimes lymphangioscintigraphy. ${ }^{3}$ Abnormal communication between the thoracic duct and the pericardial cavity is supposed to be the underlying pathophysiologic mechanism. It is practically unknown in which cases chylopericardium occurs because the principle that thoracic duct pressure has to exceed $15 \mathrm{~cm}$ of water to have a reverse flow in lymphatic tributaries is not always true. Animal ligation experiments have demonstrated that chylopericardium does not necessarily occur, even with an obstruction of the thoracic duct, because the duct can drain through collaterals to the azygous venous system. ${ }^{4}$ In this context lymphangiomatous hamartoma possibly has no direct causative relation to the chylopericardium. Because the lesion is diffuse and ill-defined, total resection is not easily achievable. The patient had remission of his pericardial effusion after the pericardial fenestration and during total parenteral nutrition, and therefore it is not evident which therapeutic

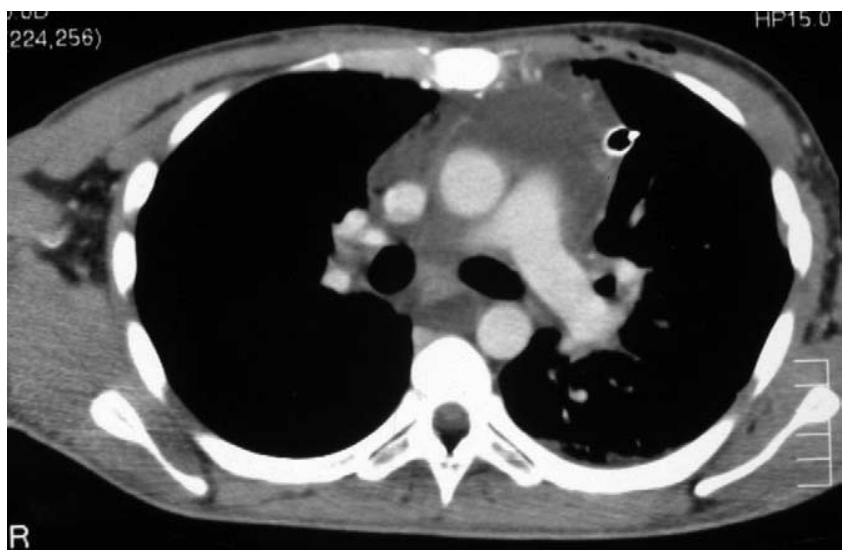

Figure 2. Thoracic computed tomographic scan revealing a mass anterior to the heart and a drainage tube into the pericardial fenestration to the left.

maneuver helped him more. In our opinion the pericardial fenestration relieved tamponade, the parenteral nutrition diminished the chylous effusion, and the lymphangiomatous hamartoma was just the innocent bystander of the disease, the nature and mechanism of which remain unknown.

Because cases of chylopericardium are extremely rare, the material is not homogenous, and the management depends on the particularities of each case, on the underlying pathology, and on the performance status of the patient. ${ }^{1,2}$

Consequently, on the basis of the available diagnostic and therapeutic modalities, it is not feasible to anticipate the most efficacious way to access a patient with chylopericardium. It seems that management has to be individualized because in many patients with mild symptoms, the disease behaves aggressively with recurrent episodes, whereas in others with severe clinical features or cardiac tamponade on arrival, the disease has a benign clinical course.

The successful outcome of this case does not predict repetitive favorable prognosis in all similar cases. We might be missing some critical points in the cause, the pathophysiology, and the underlying causative mechanism of this rare entity.

\section{References}

1. Furrer M, Hopf M, Ris HB. Isolated primary chylopericardium: treatment by thoracoscopic thoracic duct ligation and pericardial fenestration. J Thorac Cardiovasc Surg. 1996;112:1120-1.

2. Svedjeholm R, Jansson K, Olin C. Primary idiopathic chylopericardium-a case report and review of the literature. Eur J Cardiothoracic Surg. 1997; 11:387-90.

3. Nanjo S, Yamazaki J, Tsubuku M, Ohyama T, Ohtsuka T, Nakano H. Primary idiopathic chylopericardium: report of two cases. Ann Nucl Med. 2004;18:537-9.

4. Mahon NG, Nolke L, McCann H, Sugrue D, Hurley J. Isolated chylopericardium. Surgeon. 2003;1:236-8. 